\title{
SOBRE AS ORIGENS DA FAVELA
}

\author{
the origins of the 'favela' \\ Alfredo Pereira de Queiroz Filho*
}

\begin{abstract}
Resumo
Este trabalho aborda as origens da favela. Investiga o contexto de surgimento das suas edificações e do nome que passou a caracterizar esse tipo de assentamento precário no final do século XIX, no Rio de Janeiro. As evidências mostram que o surgimento dos barracos está relacionado à rápida expansão populacional e ao déficit habitacional da Capital Federal, na época. O substantivo favela é considerado originário do topônimo Alto da Favela, elevação localizada ao sul da vila de Belo Monte, cenário da Guerra de Canudos. Favela é o nome popular de uma planta, comum no sertão baiano, local dos combates. A espécie descrita por Euclides da Cunha, em Os Sertões, deve ser a Cninodoscolus quercifolius. Das interpretações para a substituição do nome do morro carioca, de Providência para Favela, realizada pelos ex-combatentes, a mais plausível é a que resgata aspectos estratégicos e topográficos. No morro da Favela, em Canudos, as tropas republicanas sofreram uma emboscada e sua ocupação foi muito importante para derrotar os seguidores de Antonio Conselheiro. A topografia está associada a uma metáfora entre as privações da tropa durante e após os combates. As dificuldades naturais da batalha, agravadas pelas características físicas do sertão, foram relacionadas à luta pelo recebimento dos soldos atrasados, após o término da guerra.
\end{abstract}

Palavras-chaves: Favelas, Assentamentos Precários, Cninodoscolus Quercifolius, Canudos, Rio de Janeiro.

\begin{abstract}
This paper focuses upon the origins of the Brazilian shantytown (favela). It investigates the context of the appearance of the housing and of the name itself which came to characterize this form of precarious settlement in Rio de Janeiro at the end of the 19th century. Evidence suggests that the appearance of the shacks was related to the population explosion and the lack of housing in what was the Federal Capital at the time. The name 'favela' is considered to have its origins in the place name 'Alto da Favela', a district on high ground located to the south of the town of Belo Monte, in the North-eastern state of Bahia, which was the site of the 'War of Canudos' uprising. 'Favela' is also the popular name for a plant, common to the outback of Bahia where the fighting took place. The species described by Euclides da Cunha, in his book 'Os Sertões', is probably the Cninodoscolus quercifolius. Of the many theories concerning the renaming of the hill district 'Providência' as 'Favela' by those who had been involved in the uprising, the most plausible is that it recalls strategic and topographic features. On the 'Favela' hill in Canudos, the Republican troops were ambushed, and the occupation was extremely important in the defeat of Antonio Conselheiro's followers. The topography is associated with a metaphor for the deprivation suffered by the troops during and after the fighting. The natural difficulties of the battle, compounded by the physical characteristics of the outback, were related to the struggle the soldiers had in receiving their pay once the war had ended.
\end{abstract}

Key words: Favelas, Precarious Settlements, Cninodoscolus Quercifolius, Canudos, Rio de Janeiro.

\section{Résumé}

Ce travail porte sur les origines de la favela. Il étudie le contexte où ont surgi ces constructions ainsi que le nom caractérisant ce genre d'agglomération précaire à la fin du XIX e siècle, à Rio de Janeiro. Tout indique que le surgissement des baraquements est en rapport avec la rapide expansion de la population et la pénurie d'habitations dans la capitale fédérale à l'époque. On estime que le substantif favela tire son origine du toponyme Mont de la Favela, une éminence située au sud de la bourgade de Belo Monte, théâtre de la guerre de Canudos. Favela est le nom vulgaire d'un arbuste commun dans le sertão (arrière-pays) de la Bahia où ont eu lieu ces combats. L'espèce décrite par Euclides da Cunha dans " Os sertões » semble être le Cninodoscolus quercifolius. Parmi les interprétations données à la substitution, opérée par les anciens combatants, du nom Providence donné jusque là au morne carioca par celui de Favela, la plus plausible est celle qui fait référence à des aspects stratégiques et topographiques. Les troupes de la République étant tombées dans une embuscade sur le mont de la Favela, son occupation fut très importante pour vaincre les partisans d'Antonio Conselheiro. Pour la topographie, un parallèle s'est établi métaphoriquement entre la situation de la troupe durant et après les combats : d'un côté les difficultés naturelles de la bataille aggravées par les caractéristiques physiques du sertão, de l'autre, la lutte menée pour la réception des arriérés des soldes après la fin de la guerre.

Mots-clés: Favela, Agglomération Précaire, Cninodoscolus quercifolius, Canudos, Rio de Janeiro.

(*) Prof. Dr. do Departamento de Geografia da Universidade de São Paulo - Av. Prof. Lineu Prestes, 338, CEP: 05.508-000, São Paulo (SP), Brasil, Tel: (+ 55 11) 3091-3769 - aqueiroz@usp.br 


\section{INTRODUÇÃO}

Em 2001, conforme UN-Habitat (2003), 924 milhões de pessoas - ou seja, 31,6\% da população urbana mundial, moravam em assentamentos precários (slums). Dentre os diferentes tipos de assentamentos precários que ocorrem no mundo, a favela se destaca como um grave e crescente problema urbano brasileiro.

A quantidade desse tipo de assentamento precário aumentou de forma explosiva a partir da década de 1960 (DAVIS, 2006). Em 2000, de acordo com Pasternak (2008), o Brasil possuía 1.650 .548 domicílios favelados, que cresciam a uma taxa anual de $4,18 \%$. No mesmo período, os outros tipos de domicílios aumentaram em uma taxa anual de $2,8 \%$.

A gravidade desse fenômeno contrasta com a qualidade dos dados sobre o assunto. As estimativas oficiais brasileiras são conflitantes, as definições de favela são inúmeras e a quantidade de documentos históricos sobre o início do processo de favelização é reduzida. Independentemente desses problemas, pesquisadores como Abreu e Vaz (1991), Abreu (1994), Vaz (1994 a e b), Chalhoub (1996), Valladares (2000 e 2005) e Pasternak (2006 e 2008) deram contribuições fundamentais aos estudos sobre os cortiços e as favelas, os dois principais tipos de assentamentos urbanos precários do país.

É nesse contexto que o artigo se insere. Seu objetivo é aprofundar as análises sobre a gênese da favela no Brasil. A investigação destaca as origens das edificações precárias que a caracteriza e a procedência da sua denominação. Para isso, o trabalho discute as circunstâncias do surgimento dos barracos e as interpretações sobre a sua associação ao topônimo do sertão baiano, no final do século XIX, na cidade do Rio de Janeiro.

\section{AS ORIGENS DAS EDIFICAÇÕES PRECÁRIAS}

O crescimento vertiginoso das favelas, no Brasil, está diretamente relacionado ao processo de urbanização, indissociável do período de intensa industrialização, particularmente nas décadas de 1950 a 1970. No entanto, o surgimento da favela é muito anterior ao fenômeno recente de concentração urbana no país.

Embora seja possível considerar que o surgimento das habitações urbanas precárias, no Brasil, date do início da colonização portuguesa, as referências aos assentamentos denominados como favela estão associadas ao contexto histórico da cidade do Rio de Janeiro, no século XIX.

A transferência da capital do Estado do Brasil da Bahia para o Rio de Janeiro veio, assim, corroborar o caráter central que esta cidade e seus governadores vinham assumindo desde meados do século XVII, cabeça ou locus articulador de vastos territórios, interesses, negócios e políticas na América e no Atlântico-Sul. Em 1808, num extraordinário jogo de inversão, o Rio de Janeiro se tornaria corte e capital da monarquia portuguesa, redimensionando os elementos e o significado de sua capitalidade. (BICALHO, 2011).

De acordo com Cardoso (2008), as habitações populares no século XIX eram predominantemente denominadas de cortiços, estalagens ou casas de cômodos. Essas moradias, que abrigavam grande número de habitantes, foram associadas à insalubridade e propagação de epidemias, como febre amarela e cólera, à promiscuidade e à violência.

Para Vaz (1994b), essas moradias coletivas foram uma resposta à crise urbana, causada, sobretudo, pelo crescimento demográfico intenso e o déficit habitacional. No Rio de Janeiro, a população mais do que dobrou de tamanho entre 1870 e 1890 (de 235.381 para 518.292 habitantes). Com a elevada procura de moradia nas freguesias centrais, os quintais e terrenos livres deram lugar a pequenas casas e as antigas casas foram subdivididas em cômodos. 
Nesse sistema, os proprietários cediam seus imóveis (térreos, sobrados, quintais e terrenos) a terceiros que investiam pequenas economias na construção de casinhas ou na subdivisão das existentes. Os proprietários pertenciam muitas vezes à nobreza, e os arrendatários eram pequenos comerciantes, geralmente portugueses, que produziam casinhas e exploravam também a venda ou a taverna anexa à estalagem. (...) Os aluguéis eram, em geral, exorbitantes e os rendimentos, fabulosos. Construir habitações coletivas tornou-se uma prática comum entre os proprietários e arrendatários de imóveis. (VAZ, 1994b p.56).

É muito provável que o uso da palavra cortiço, para caracterizar as habitações coletivas, seja oriundo da associação que se fazia entre as estalagens e as colméias (VAZ, 1994a). O cortiço é um tipo de caixa cilíndrica, de cortiça, usada como abrigo das abelhas no processo de produção de mel. A cortiça é a casca da árvore popularmente conhecida como Sobreiro (Quercus suber), que os antigos apicultores lusitanos extraiam para fabricar os abrigos das colméias. Segundo a autora, a grande densidade de ocupantes, os seus minúsculos compartimentos e os ruídos decorrentes são os aspectos mais relevantes dessa relação (habitação/colméia).

O "Cabeça de Porco", o maior cortiço carioca da época, da mesma forma que os outros cortiços do centro urbano da cidade eram considerados como um "valhacouto de desordeiros" pelas autoridades (CHALHOUB, 1996). Ficou famoso por causa das suas dimensões. As estimativas mais elevadas mencionam cerca de 4.000 moradores e, as mais ponderadas, 2.000. Contudo, do ponto de vista do tamanho, era uma exceção à regra, pois predominavam, no Rio de Janeiro, pequenas estalagens com menos de dez quartos ou casinhas.

Para Vaz (1994b), o Cabeça de Porco foi alvo de inúmeras investidas do poder público, que buscava impor medidas de higiene nesses tipos de moradia. Ainda segundo a autora, foi o único cortiço comprovadamente demolido pelo poder público (1893). Nem mesmo a importância dos proprietários - há boatos de que pertenceria ao Conde d'Eu, marido da princesa Isabel - e a resistência dos moradores impediram a operação de guerra deflagrada pela administração municipal contra esse cortiço, que se tornara um símbolo de degradação.

Há indícios de que foram construídos barracões no Morro da Providência, logo após a destruição do Cabeça de Porco. Além do cortiço se localizar no sopé do referido morro, pelo menos um dos proprietários do cortiço possuía terrenos no morro e, mediante pagamento dos inquilinos, autorizou a construção de edificações na vertente. A autorização municipal para que os moradores retirassem os materiais provenientes da demolição, pode ser considerada outra evidência dessa relação (VAZ,1994b).

Assim, o cortiço pode ser considerado a "semente da favela". Essa afirmação, de Vaz (1994a), reforça a idéia de que o problema habitacional não foi resolvido na época, e que as iniciativas municipais para erradicar os cortiços deram origem às ocupações dos morros.

Essa relação também é compartilhada por Cardoso (2008). Segundo o autor, inúmeras ações governamentais foram tomadas para acabar com os cortiços. Uma que se destacou foi a reforma urbana do prefeito Pereira Passos (1902-1906), conhecida popularmente como "Bota-abaixo", que visava o saneamento e o urbanismo. Essa referida política de eliminação dos cortiços obteve sucesso no Rio de Janeiro,

No entanto, o "sucesso" da erradicação significou tão-somente a transferência do problema para outros lugares: na falta de outras opções a população de baixa renda, na maioria das cidades brasileiras, sobe os morros ou ocupa as áreas de mangues e alagados, pouco valorizadas pelo mercado fundiário incipiente, gerando o "problema" das favelas (vilas, mocambos, palafitas, malocas, invasões, baixadas etc.). (CARDOSO, 2008 p.29).

Em linhas gerais, Abreu (1994) reforça essa abordagem, mas adiciona o papel dos militares entre as circunstâncias das ocupações dos morros. Para o autor, a origem da favela está relacionada 
à crise habitacional e às crises políticas do início da República (Revolta da Armada, de 1893-1894 e Guerra de Canudos, 1896 a 1897).

A dificuldade de alojar os soldados no Rio de Janeiro "agravou-se" após a rebelião de unidades da Marinha contra o governo do Marechal Floriano Peixoto (Revolta da Armada). Dada a deficiência de casas nas proximidades do quartel, e considerando que a ocupação do convento de Santo Antônio, pelo $7^{\circ}$ Batalhão, não foi suficiente para abrigar os militares, foi autorizada a construção de diversos barracões de madeira na encostas do morro de Santo Antônio (ABREU, 1994).

O exemplo do morro de Santo Antonio é ilustrativo. Em 1897 já havia neste morro 41 barracões construídos por soldados do $7^{\circ}$ Batalhão de Infantaria de Linha do Exército com autorização do Coronel Antonio Moreira Cesar (AGCRJ 67-1-25). Quatro anos mais tarde, entretanto, estes barracões já formavam, segundo o Jornal do Comércio, um "bairro novíssimo". (ABREU; VAZ, 1991 p.489).

Os problemas habitacionais relacionados à caserna são, no entanto, mais antigos. O retorno das tropas da Guerra do Paraguai (1864-1870), por exemplo, contribuiu com o déficit de moradias da Capital.

Até então, nas palavras de Cunha (2000 p.33), "o integrante do Exército sofria o estigma da degradação social; os recrutados eram obtidos junto aos elementos marginalizados da população". Em decorrência, para recrutar um grande contingente de soldados, o governo ofereceu recompensas para os que se alistassem. O artigo segundo da lei 3.371, de 1865, conhecida como Lei Voluntários da Pátria, dizia que:

Art. $2^{\circ}$ - Os voluntários que não forem Guardas Nacionais terão, além do soldo que recebem os voluntários do exército, mais 300 réis diários e a gratificação de $300 \$ 000$, quando derem baixa e prazo de terras de 22.500 braças quadradas nas colônias militares ou agrícolas. (CUNHA, 2000 p.32).

Para ampliar o contingente nacional no cenário de combate, foi promulgado o decreto 3.725, de 06 de novembro de 1866, que libertava os escravos que tinham condições de servir ao Exército. Os benefícios, como a pensão, foram estendidos às mulheres dos que fossem casados (CUNHA, 2000 p.45). Esse conjunto de circunstâncias, após o final da Guerra da Tríplice Coroa, contribuiu de maneira significativa para agravar o problema habitacional do Rio de Janeiro.

De outro ponto de vista, Medina (1964) considera que as duas principais explicações para o surgimento das favelas foram a abolição da escravatura e a crise na agricultura. $\mathrm{O}$ autor considera que a abolição, em 1888, trouxe muitas alegrias, mas foi um gesto humano que não teve continuadores. Destaca que seu advento não modificou a realidade agrária do país. O trabalhador rural não era valorizado, mas equiparado a uma enxada ou animal. Assim, a "única liberdade que os escravos receberam foi a de poderem ser móveis. Isto é, sair da fazenda onde moravam, para onde quisessem, sem serem perseguidos por 'capitães do mato'.” (MEDINA, 1964 p.16).

Com a crise da agricultura, nesse contexto, uma quantidade expressiva de proprietários de terras procurou os centros mais importantes para se fixarem. Essa atitude não só mostrava aos empregados um caminho a ser seguido, como desintegrava os antigos laços afetivos entre senhores e escravos. A distância afastava os proprietários dos problemas da fazenda e das questões pessoais dos trabalhadores, enfraquecendo um arraigado sistema de relações sociais. A criação de gado, que empregava um contingente muito menor, passou a ser uma alternativa financeira à agricultura, que por sua vez, contribuiu para migração dos trabalhadores para as grandes cidades, em busca de trabalho (MEDINA, 1964).

\section{AS ORIGENS DA PALAVRA}

Favela é o nome popular atribuído a diferentes plantas brasileiras. Ao que tudo indica, a espécie da família Euphorbiaceae passou a caracterizar os agrupamentos de domicílios urbanos precários 
graças a um contexto geográfico e histórico muito peculiar. Esse conjunto de circunstâncias pode ser sintetizado pelo encadeamento de quatro principais elementos: planta, topografia, combate e narrativa.

\section{Contexto da denominação}

A ocorrência da planta favela deu nome a uma encosta do arraial de Belo Monte de Canudos, o Alto da Favela (Figura 1). Nessa vila, localizada no semi-árido baiano (Figura 2), aconteceram violentos combates no final do século XIX, início do período republicano no Brasil.

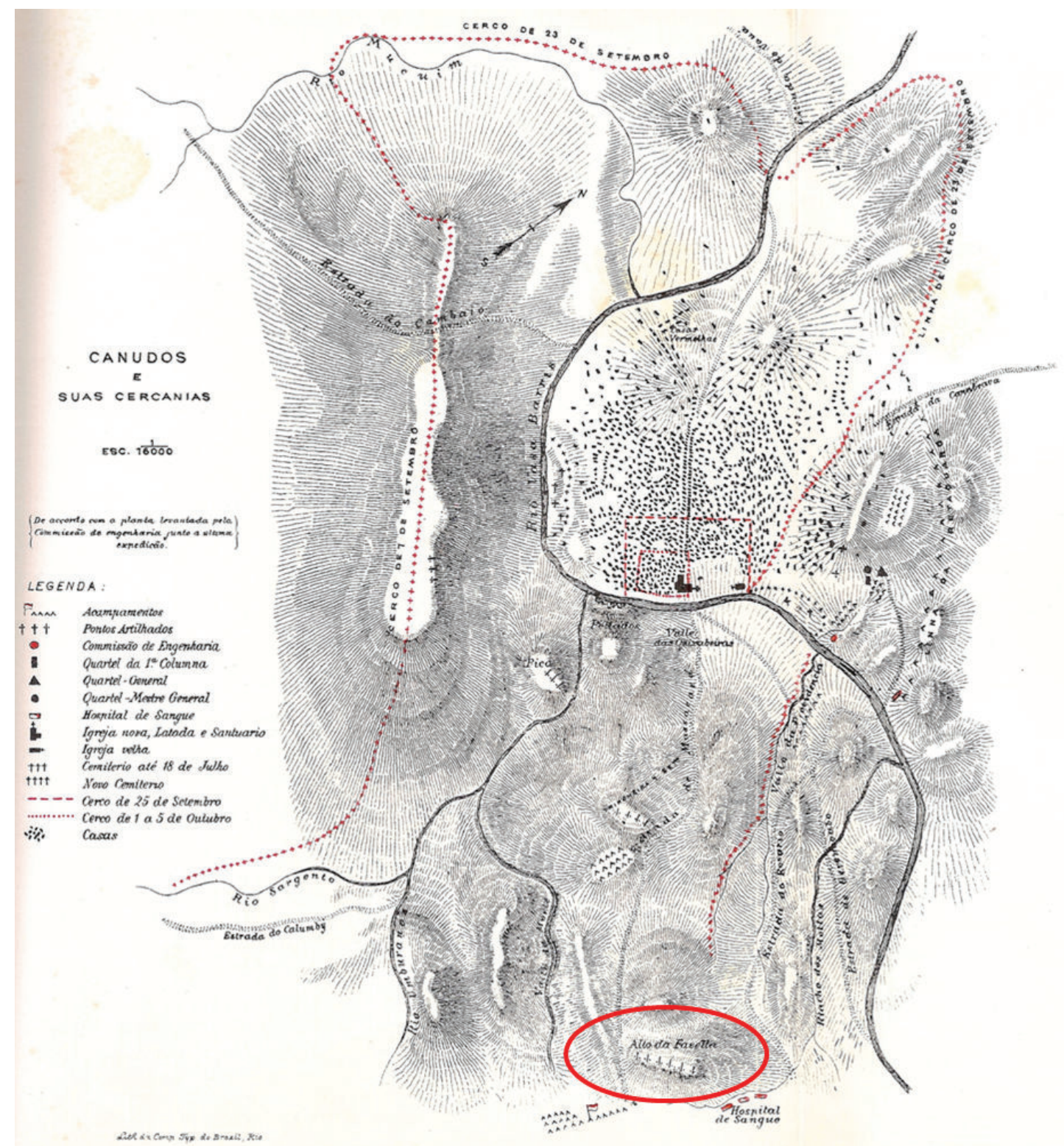

Figura 1: Alto da Favela no extremo sul da vila de Canudos Fonte: Cunha (1985) 


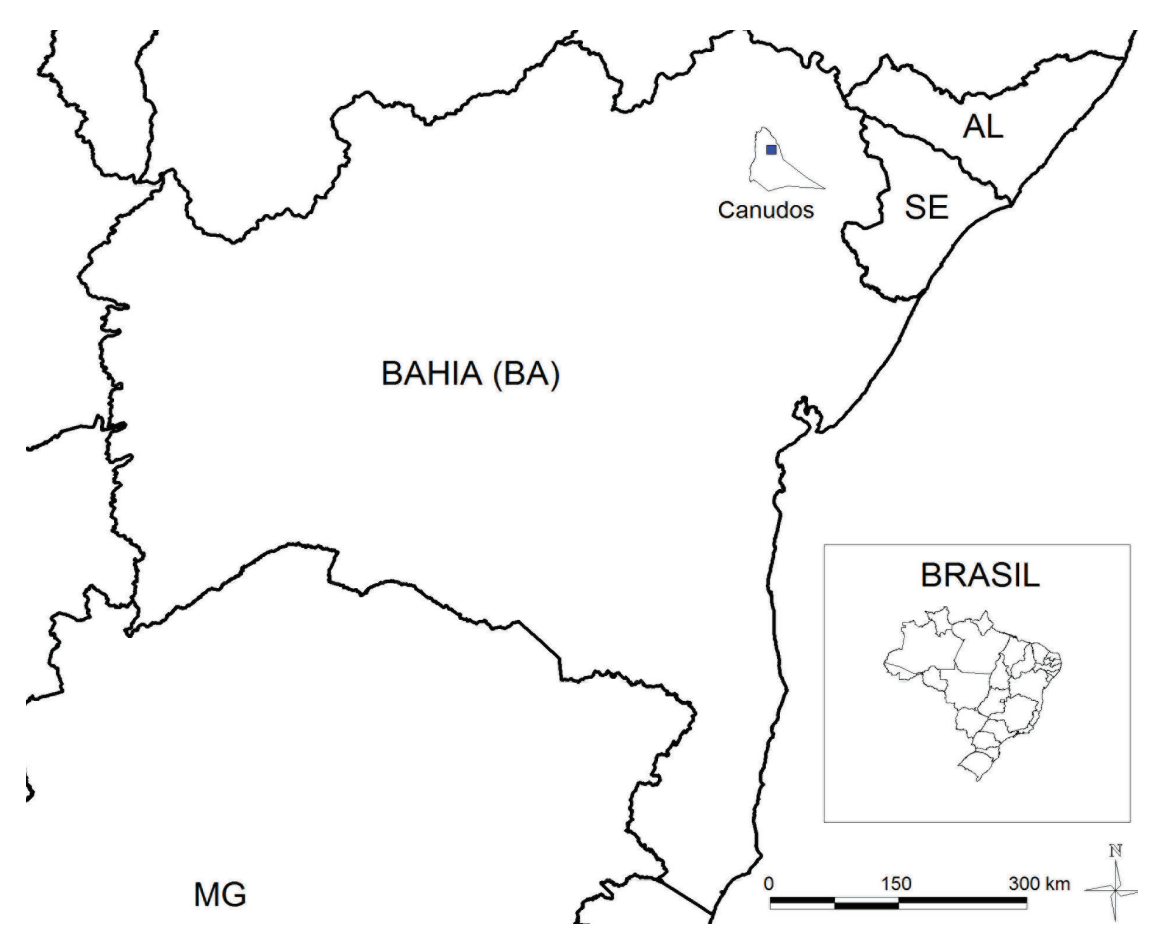

Figura 2: Localização do município de Canudos - BA Fonte: IBGE (2005)

Belo Monte foi o cenário da Guerra de Canudos, na qual se confrontaram o Exército Brasileiro e os integrantes de um movimento popular religioso liderado por Antônio Conselheiro.

Quatro expedições militares combateram os partidários do beato penitente. Os combates ocorreram entre 1896 e 1897, causando baixas de aproximadamente 20.000 insurgentes e 5.000 militares. As repercussões desse insólito conflito, enormes para o país, foram eternizadas pela obra prima do escritor Euclides da Cunha, "Os Sertões", de 1902.

De acordo com Cruz (1941), a origem da palavra favela está associada à Guerra de Canudos.

A favela tem sua toponímia ligada à chamada "guerra de Canudos". Terminara a luta na Baía. Regressavam as tropas que haviam dado combate e extinguiram o fanatismo de Antônio Conselheiro. Muitos soldados solteiros vieram acompanhados de "cabrochas". Elas queriam ver a Côrte...

Êsses soldados tiveram de arranjar moradas. Foram para o antigo morro de S. Diogo e, aí, armaram o seu lar. As "cabrochas" eram naturais de uma serra chamada Favela, no município de Monte Santo, naquele Estado. Falavam muito, sempre da sua Baía, do seu morro. E aí ficou a Favela nas terras cariocas. Os barracões foram aparecendo, um a um. Primeiro, na aba da Providência, morro em que já morava uma numerosa população; depois, foi subindo, virou para o outro lado, para o Livramento.

Nascera a Favela. 1897 (CRUZ, 1941 p.14).

De acordo com Sagmacs (1960), a palavra favela teria sido trazida de Canudos para o Rio de Janeiro. Encerrados os combates em Canudos, parte dos soldados sobreviventes e das vivandeiras (mulheres que acompanham as tropas e fornecem comestíveis) se instalou no Morro da Providência, no Rio de Janeiro, capital do país na época. Também trouxeram uma cruz, que foi instalada numa pequena capela no topo do morro, em devoção a Antônio Conselheiro. Uma das decorrências dessa ocupação foi o surgimento do novo nome para o local, o Morro da Favela.

Para Medina (1964), o Morro da Providência foi rebatizado como Morro da Favela pelos seus novos ocupantes não só em homenagem ao ponto estratégico que permitiu a vitória das tropas republicanas em Canudos, mas também para ilustrar as semelhanças entre as circunstâncias vivenciadas no sertão e na capital federal. A topografia de ambos era semelhante, pois era considerada uma elevação que permitia visualizar o "inimigo" nas diferentes épocas (Antônio Conselheiro e 
o Ministério da Guerra). As privações da guerra podiam ser comparadas ao desamparo dos ex-combatentes, pois o pagamento dos soldos e pensões aos sobreviventes e inválidos estava atrasado. Como numa metáfora, as incursões diárias contra os inimigos da República em Canudos (seguidores de Conselheiro) foram associadas à batalha contra a má vontade e a indiferença do Quartel General do Exército, localizado próximo ao sopé do Morro da Providência (Figura 3).

Do ponto de vista militar, outro elemento que reforça o aspecto estratégico do morro da Favela é a descrição de um dos combates da quarta expedição militar em Canudos. De acordo com Cunha (1985 p.401), os insurgentes causaram 75 baixas nas tropas republicanas:

Aquilo era uma armadilha singularmente caprichosa. Quem percorresse mais tarde as encostas da Favela avaliava-a. Estavam minadas. A cada passo uma cava circular e rasa, protegida de tosco respaldão de pedras, demarcava uma trincheira. Eram inúmeras; e volvendo todas para a estrada os planos de fogo quase à flor da terra, indicavam-se adrede dispostas para um cruzamento sobre aquela. (CUNHA, 1985 p.399).

Além do aspecto topográfico e estratégico, Zylberberg (1992) menciona outra semelhança toponímica entre Canudos e o Rio de Janeiro. O rio da Providência estava presente na região dos combates e, o morro da Providência, na Capital Federal.

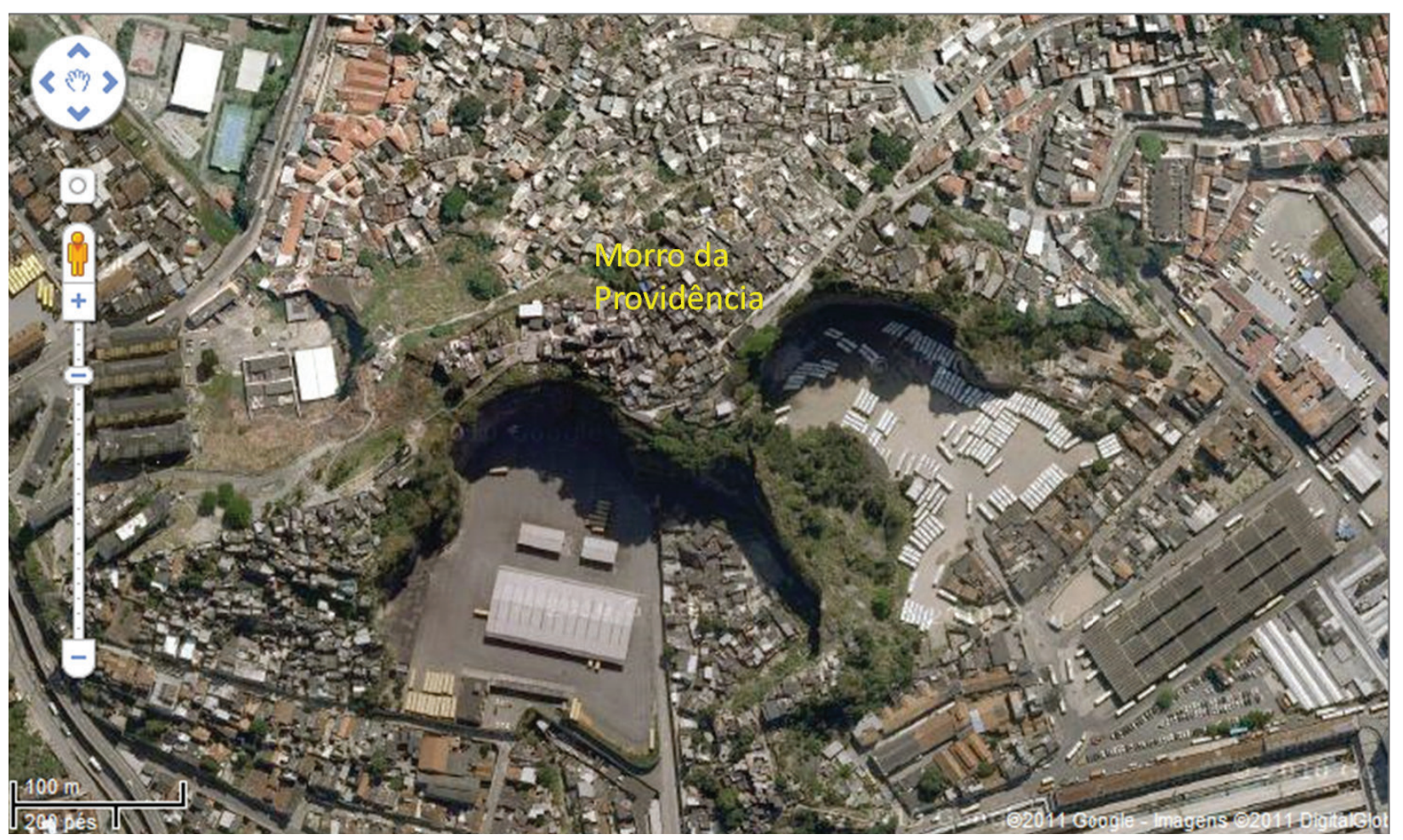

Figura 3: Localização atual do Morro da Providência - RJ Fonte: GoogleMaps (2011)

Para Valladares (2000), a origem do termo também está associada à ocupação do Morro da Providência, no final do século XIX, por ex-combatentes da Guerra de Canudos que buscavam pressionar o Ministério da Guerra a pagar os soldos atrasados. A autora apresenta também uma compilação das interpretações sobre essa denominação: 1) a favela, espécie que denominou a vertente de Canudos, também ocorria no morro carioca; 2) a associação da forte resistência dos soldados de Antonio Conselheiro entrincheirados no morro da Favela, durante a Guerra de Canudos, aos habitantes do morro carioca. 
Pasternak (2006) destaca a semelhança da ocorrência da planta e dos barracos. De acordo com a autora, soldados do exército brasileiro retornaram ao Rio de Janeiro, após o fim da Guerra de Canudos, e ocuparam "o Morro da Providência, onde se instalaram em barracos como o arbusto favela nos morros da região de Canudos" (PASTERNAK, 2006 p.179).

Independentemente das distintas interpretações para a denominação do morro, houve um processo posterior e gradativo de generalização do seu significado. Assim como numa metáfora, figura de linguagem na qual uma palavra substitui outra em vista de uma relação de semelhança, a palavra favela passou a ser utilizada de forma mais ampla.

Para Vaz (1994b), o nome próprio se tornou substantivo, ou seja, o nome do morro passou a ser utilizado pelos jornais, na década de 1920, para caracterizar esse tipo de ocupação. Da mesma forma, Abreu (1994) considera que a palavra favela tornou-se um nome genérico para denominar assentamentos precários na segunda década do século XX.

Conforme Vaz (1994b), as favelas foram reconhecidas oficialmente a partir da década de 1940. Para Valladares (2005) o reconhecimento oficial da existência das favelas já estava presente no Código de Obras do Rio de Janeiro, em 1937.

A popularização da palavra favela, para muitos autores, não está vinculada somente às referências geográficas de Canudos ou históricas sobre a batalha final, mas também ao enorme impacto da obra "Os sertões", de Euclides da Cunha, em diferentes segmentos da sociedade brasileira. O escritor acompanhou, a pedido do jornal "O Estado de São Paulo", a 4 Expedição contra Canudos, em 1897. Cinco anos depois (1902), publicou o clássico que narra a Campanha de Canudos.

A gênese do processo de construção social da favela está associada às descrições e imagens legadas por escritores, jornalistas e reformadores sociais do início do século XX. Sua divulgação, no período, possibilitou o "desenvolvimento de um imaginário coletivo sobre o microcosmo da favela e seus moradores" (VALLADARES, 2000 p.8). Ainda segundo a autora, essa imagem também foi reforçada pelos primeiros visitantes da favela do Rio, quando suas descrições transpuseram as dualidades 'litoral versus sertão' para 'cidade versus favela':

$\mathrm{Na}$ verdade, era como se fossem dois mundos, e a dualidade presente na oposição "litoral versus sertão" do discurso euclidiano transparece nessas primeiras imagens e representações sob a forma da oposição "cidade versus favela". A imagem matriz da favela estava, portanto, construída e dada a partir do olhar arguto e curioso do jornalista/observador. "Um outro mundo", muito mais próximo da roça, do sertão, "longe da cidade", aonde só se poderia chegar através da "ponte" construída pelo repórter ou cronista levando o leitor até o alto do morro que ele, membro da classe média, não ousava subir (VALLADARES, 2000 p.12).

Ainda que "Os Sertões" seja posterior à ocupação do Morro da Providência, o sucesso editorial do escritor brasileiro pode ser considerado o grande responsável pela consolidação do termo que denomina assentamentos urbanos precários.

Além disso, desde o início do século XX, existe no Rio de Janeiro uma clara associação entre as expressões "morro" e "favela". A pesquisa de Oliveira e Marcier (1998) evidencia a relação entre favela, samba, carnaval e morro. As músicas populares pesquisadas, das décadas de 1920 a 1990, mostram essa relação:

mesmo antes de ser 'favela', a favela foi morro no Rio e sua expansão na malha urbana foi fundamentalmente impulsionada pela ocupação de novos morros e/ou pelo adensamento dos antigos. Não é de estranhar, portanto, que no conjunto de 163 músicas levantadas, 93 estabeleçam uma sinonímia entre morro e favela. (OLIVEIRA, MARCIER, 1998, p. 71).

\section{Sobre a planta}

A espécie que denomina hoje os assentamentos urbanos precários, ao que tudo indica, é a Cnidoscolus quercifolius. No entanto, sua exata identificação é dificultada por três principais razões: 
1) favela é o nome popular de, pelo menos, três diferentes plantas brasileiras; 2) Euclides da Cunha mencionou e descreveu a planta, mas não a identificou; 3) há divergências entre taxonomistas sobre a classificação da planta.

Há referências à favela-branca, denominação popular de uma leguminosa (família Fabaceae), também conhecida como Angico-de-minas e Vinhático-do-campo, cujo nome em latim é Enterolobium ellipticum Benth (mencionada por VALLADARES, 2000). Existe a fava d'anta ou favela, cientificamente conhecida como Dimorphandra mollis Benth (família Fabaceae), leguminosa que ocorre no cerrado brasileiro, principalmente no norte e noroeste do estado de Minas Gerais. Também há menções à favela ou faveleiro, um arbusto/árvore da família Euphorbiaceae, gênero Cnidoscolus, espécies quercifolius e phyllacanthus.

Na busca realizada na Lista de Espécies da Flora do Brasil, elaborada pelo Instituto de Pesquisas do Jardim Botânico do Rio de Janeiro (http://floradobrasil.jbrj.gov.br/search), constatou-se que:

- A Enterolobium ellipticum não consta dessa lista. Existem 11 espécies do gênero Enterolobium, mas não há referência à espécie ellipticum;

- A Dimorphandra mollis Benth integra a lista, mas não possui referência ao nome popular (nome vernáculo) fava d'anta ou favela;

- A Cnidoscolus quercifolius é a única que possui nome vernáculo relacionado à espécie (favela-de-cachorro) ;

- A Cnidoscolus phyllacanthus, assim como a Cnidoscolus lobatus, não integram a lista de espécies, mas aparecem como sinônimos relevantes de Cnidoscolus quercifolius.

Embora não faça parte da lista do Jardim Botânico, elaborada por Cordeiro; Secco (2010), a espécie Cnidoscolus quercifolius possui outro sinônimo aceito, a Jatropha phyllacantha .

Notam-se, assim, expressivas alterações no processo de classificação da planta. Essas divergências entre os taxonomistas, entretanto, podem ser consideradas como inerentes da evolução das pesquisas dessa área de estudo. Atualmente, a discordância entre os pesquisadores se reduziu muito (Melo, Sales, 2008), mas ainda é comum encontrar referências antigas à planta, que deixaram de ser aceitas pelos especialistas.

Como se pode observar na citação a seguir, Euclides da Cunha desconhecia a planta, mas sua detalhada descrição foi muito útil para auxiliar na identificação da espécie. Segundo o escritor:

As favelas, anônimas ainda na ciência - ignoradas dos sábios, conhecidas demais dos tabaréus - talvez um futuro gênero cauterium das leguminosas, têm, nas folhas de células alongadas em vilosidades, notáveis aprestos de condensação, absorção e defesa. Por um lado, a sua epiderme ao resfriar-se, à noite, muito abaixo da temperatura do ar, provoca, a despeito da secura deste, breves precipitações de orvalho; por outro, a mão que a toca, toca uma chapa incandescente de ardência inaturável. (CUNHA, 1985 p.121).

O levantamento bibliográfico reforçou as evidências de que a descrição de Euclides da Cunha refere-se à espécie Cnidoscolus quercifolius, muito comum na maior parte do sertão e endêmica da caatinga hiperxerófila. Conforme Melo e Sales (2008), a favela, também conhecida como faveleira, faz parte da família Euphorbiaceae, o mesmo grupo de plantas da seringueira, da mamona e da mandioca.

Ainda segundo os autores, outro indicador de que a favela seja a Cnidoscolus quercifolius (Figuras 4, 5a e 5b) é a correspondência da descrição: "tem as folhas de células alongadas em vilosidades, notáveis aprestos de condensação, absorção e defesa". Euclides se refere aos tricomas (pelos) da planta, que são longos e ocos. São compostos por uma célula longa em forma de agulha que contém um líquido interno, extremamente urticante, podendo provocar fortes dores, coceira 
e ardência ("por outro, a mão que a toca, toca uma chapa incandescente de ardência inaturável"). Existem outras espécies do gênero Cnidoscolus, igualmente urticantes, mas a mais popular e denominada de favela é a C. quercifolius. Além disso, nenhuma das espécies de Leguminosae do Sertão apresenta características semelhantes, muito menos os representantes do gênero Enterolobium.

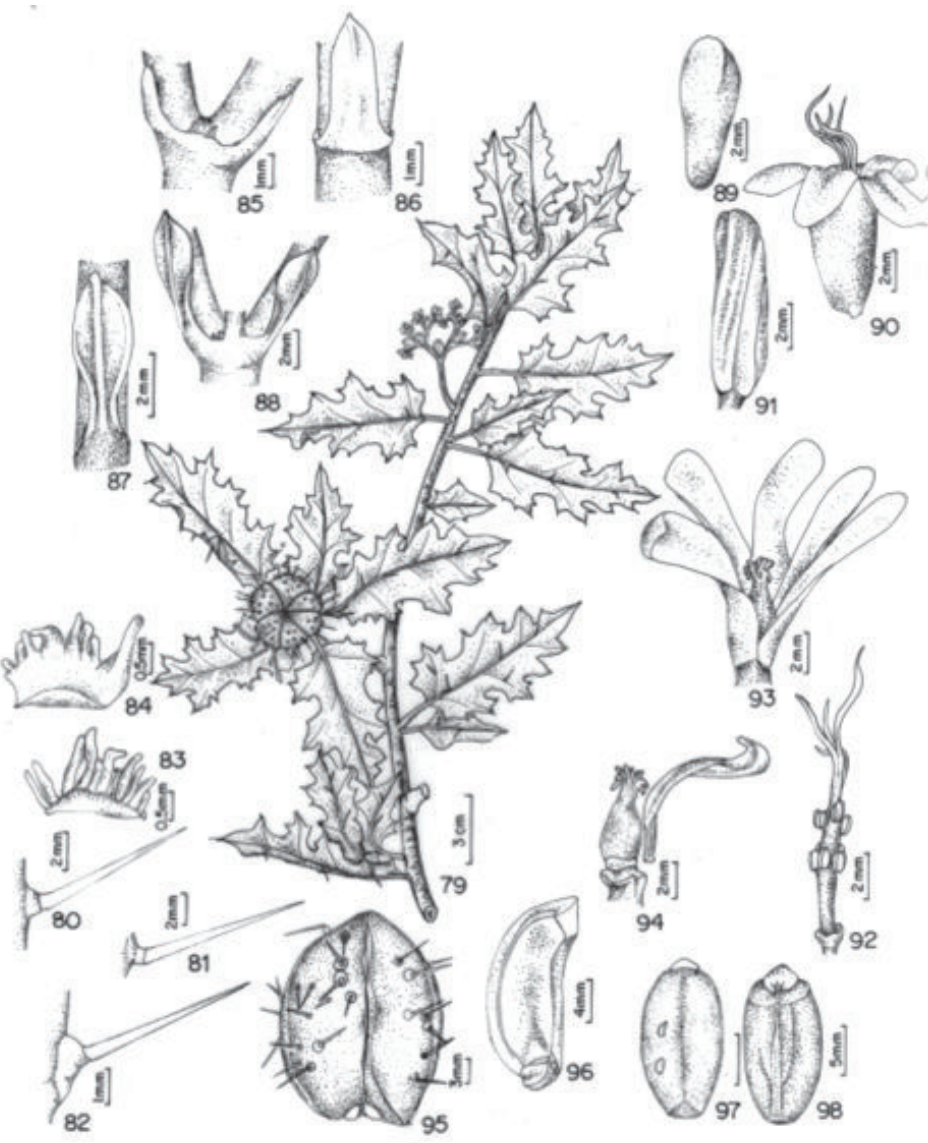

Figura 4: Ilustrações da planta Cnidoscolus quercifolius Fonte: Melo; Sales (2008)

A identificação da planta poderia ser ainda mais conclusiva com um trabalho de campo. No entanto, o ambiente local foi bastante alterado pelo fato de a vila de Canudos ter sido inundada pelas águas do açude de Cocorobó (Figura 6). O núcleo denominado de Canudos Velho (Figura 6 - A) é a área emersa mais próxima da antiga Belo Monte de Canudos (submersa). A atual cidade de Canudos localiza-se a aproximadamente 12 quilômetros ao leste da antiga vila fundada por Antonio Conselheiro (Figura 6 - B). Na realidade, esse núcleo urbano corresponde à antiga vila de Cocorobó, situada próxima à barragem do açude homônimo, que prosperou com a obra e alterou seu nome para Canudos, em 1985. 


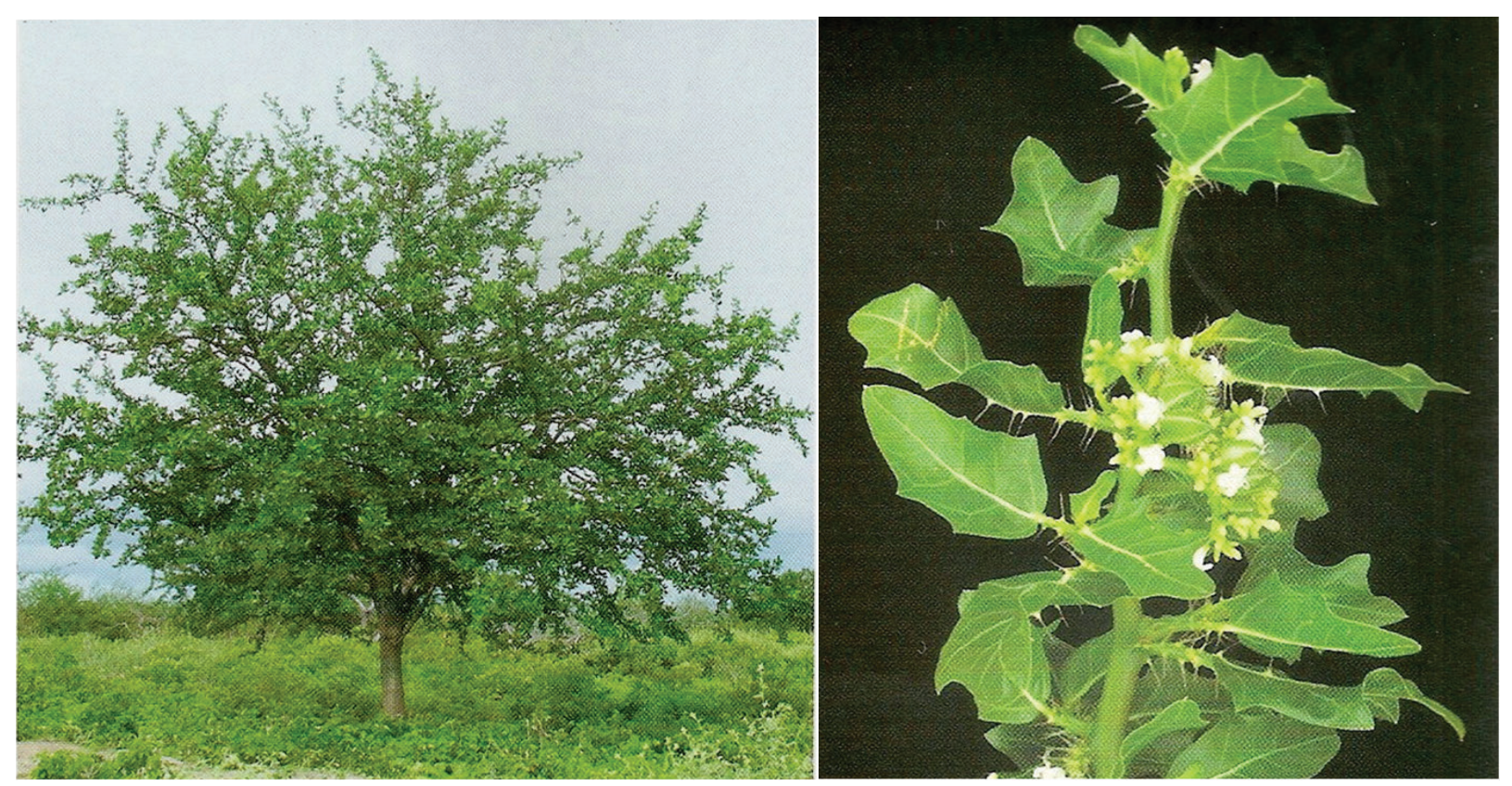

Figuras 5a e 5b: Fotografias da favela Fonte: Lorenzi (2002)

A polêmica em torno do açude foi grande, dado o significado histórico de Belo Monte de Canudos. Sua construção foi longa e interrompida inúmeras vezes. Os estudos da represa tiveram início no final da década de 1940, o local foi definido no segundo governo Vargas (1951-54), o açude foi concluído em 1967 (DNOCS, 2011) e o lago atingiu a cota prevista em 1969.

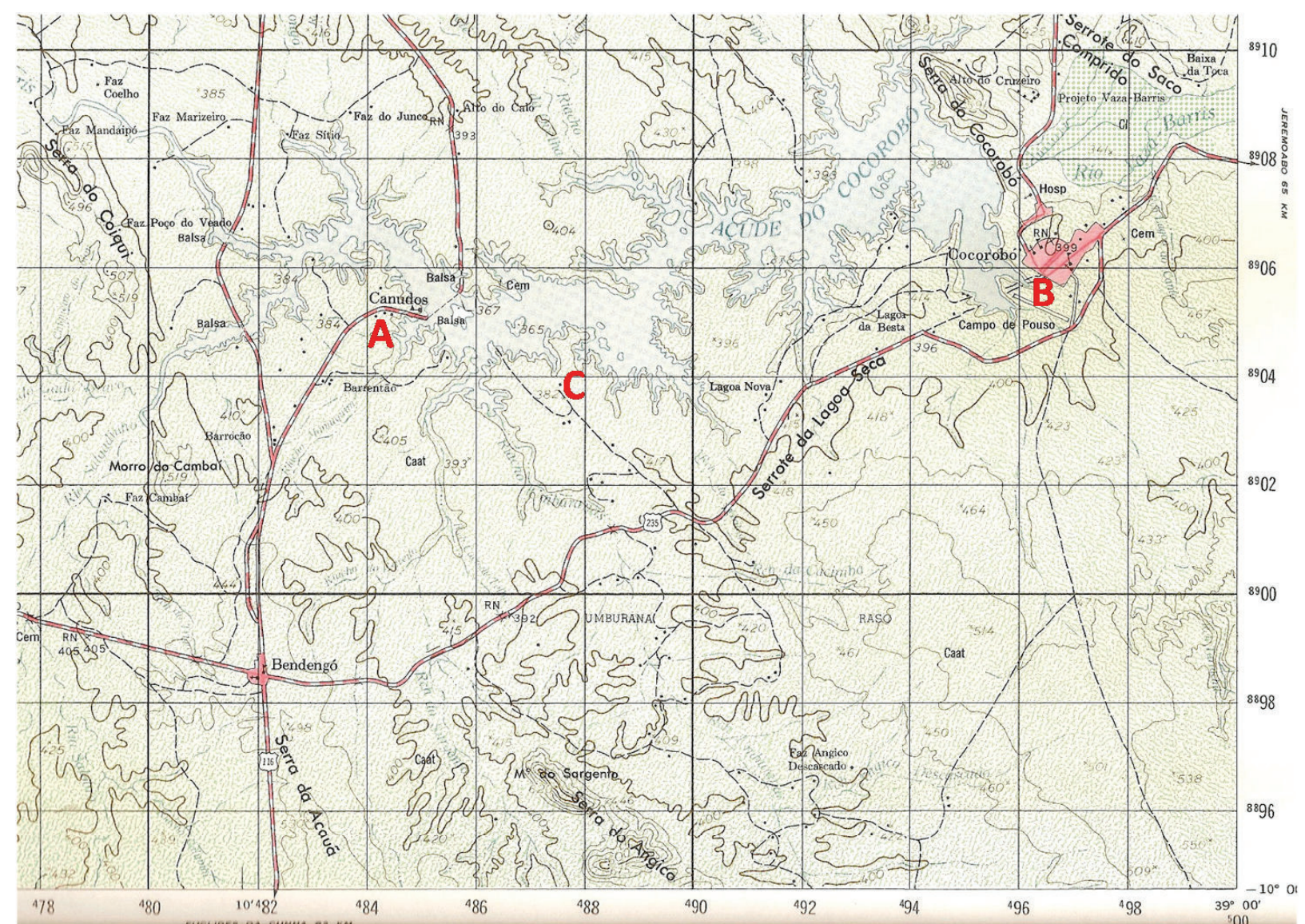

Figura 6: Parcial da carta topográfica de Uauá (1/100.000) folha SC-24-V-D-VI Fonte: DSG - Diretoria de Serviço Geográfico (1976) 
Outro elemento relevante é a escassez de relatos sobre a origem do topônimo. A suposição inicial de que o Morro da Favela (Figura 6 - C) foi assim denominado pela abundância da planta não é verdadeira. A descrição de Euclides da Cunha é clara:

Porque o Morro da Favela, como os demais daquele trato dos sertões, não tem nem mesmo o revestimento bárbaro da caatinga. É desnudo e áspero. Raros arbúsculos, esmirrados e sem folhas, raríssimos cereus ou bromélias esparsas, despontam-lhe no cimo sobre o chão duro, entre as junturas das placas xistosas justapostas em planos estratigráficos, nitidamente visíveis, expondo, sem o disfarce da mais tênue camada superficial, a estrutura interior do solo (CUNHA, 1985 p.398).

Assim, acredita-se que a planta que denominou a colina, de aproximadamente 400 metros de altitude, ocorresse de forma dispersa nas suas proximidades ou que houvesse pelo menos um indivíduo da espécie na sua encosta. Ainda que sua presença fosse menos acentuada do que se pudesse supor, foi imprescindível para o registro do topônimo no mapa publicado na primeira edição de “Os sertões”, em 1902. Esse documento cartográfico foi elaborado pela Comissão de Engenharia do Exército da $4^{\text {a }}$ Expedição Militar em Canudos, comandada pelo General Artur Oscar de Andrade Guimarães, em 1897.

\section{DISCUSSÃO}

Considera-se consenso, no que se refere à favela, de que a concentração e o crescimento do número de edificações precárias foram decorrência do rápido aumento populacional e do déficit habitacional do Rio de Janeiro, no final do século XIX.

Outra concordância relevante dos autores é que a ocorrência de assentamentos precários nos morros cariocas é anterior à sua atual denominação. Como menciona Rocha (1995 p.90), "não podemos, portanto, afirmar que a favela surge no morro da Favela, mas podemos sim, dizer que é a partir da ocupação do morro da Favela que essa prática se sistematiza".

Também há consonância sobre o papel das políticas de extinção dos cortiços como semente das favelas. Essa associação decorre da demolição do maior cortiço carioca, em 1893, o Cabeça de Porco, e o surgimento imediato de habitações precárias no Morro da Providência. Ao invés de uma solução, houve uma transformação da natureza do problema habitacional. Ao contrário dessas moradias coletivas, os assentamentos precários que viriam a ser denominados de favelas escaparam da fúria dos higienistas e urbanistas do final do século XIX e início do XX, pois sua população era pouco expressiva, as aglomerações ocorriam de forma dispersa e nas encostas dos morros.

O contexto militar da época foi outro componente importante na gênese da favela. Embora não seja consenso entre os pesquisadores, as referências convergem sobre as dificuldades das Forças Armadas em oferecer habitações para seus subordinados de menor patente. As circunstâncias do fim da Guerra do Paraguai e do encerramento da Guerra de Canudos foram muito importantes na cidade do Rio de Janeiro, pois uma parte significativa dos ex-combatentes retornou à capital, agravando ainda mais o déficit habitacional. O registro da autorização militar para que os soldados construíssem barracões no morro de Santo Antônio, por ocasião da Revolta da Armada, comprova não só o tamanho do problema habitacional da cidade, como a falta de perspectiva de solução para a moradia de praças e soldados.

Constatou-se também que não parece haver divergências sobre a origem da palavra. Essa categoria de assentamentos precários atuais é associada ao topônimo Alto da Favela, morro importante no cenário de combates da Guerra de Canudos.

Contudo, há diferentes interpretações sobre as razões da substituição do nome do morro carioca, de Previdência para Favela. Cruz (1941) refere-se às mulheres baianas que acompanharam os soldados no retorno ao Rio de Janeiro. O desejo de conhecer a corte e as lembranças das origens teria ocasionado a mudança. Sagmacs (1960) menciona a instalação de uma cruz, em devoção a 
Antônio Conselheiro. Medina (1964) faz referência à semelhança topográfica estratégica da elevação na campanha e na capital federal. Associa também ao calvário dos ex-combatentes com relação aos pagamentos atrasados. O próprio Euclides da Cunha (CUNHA, 1985) faz referência ao Morro da Favela como uma "armadilha" que surpreendeu os soldados em um dos combates da quarta expedição militar. Valladares (2000) destaca ocorrência da planta e a associação da resistência dos insurgentes de Canudos aos habitantes do morro. Pasternak (2006) relaciona a distribuição física da planta e dos barracos.

Se considerarmos que a denominação foi realizada pelos próprios moradores, a interpretação de Medina parece a mais plausível. Esse autor destaca as semelhanças da topografia e das incursões diárias dos soldados. Se boa parte dos moradores era composta por ex-combatentes, recém chegados da batalha, é provável supor razões militares nessa denominação. Considerando a revisão bibliográfica, essa alternativa é, sem dúvida, a mais factível.

A associação do Morro da Favela à emboscada que vitimou 75 soldados republicanos também corrobora a valorização do componente estratégico. Além dessa semelhança, o episódio contribuiria ainda para ressaltar um aspecto simbólico, que pode ser traduzido como a agressividade atribuída aos moradores do morro carioca.

A interpretação de Cruz (1941) ressalta o papel das mulheres baianas que acompanharam os soldados no retorno à Capital. É sensato considerar a importância do papel da lembrança recente das "cabrochas", mas é muito pouco provável que elas tivessem nascido em Belo Monte (ou Monte Santo, como menciona o autor), pois para lá migraram milhares de pessoas de diversas regiões, muito menos que fossem naturais da serra da Favela.

A interpretação de Sagmacs (1960), sobre a cruz em devoção a Antonio Conselheiro, é interessante, mas, isolada, não mostra expressividade no contexto de ocupação. Foram pouquíssimos seguidores do beato que sobreviveram e para lá se mudaram. Esse reduzido grupo, se comparado ao de ex-combatentes, não teria importância suficiente para alterar a denominação do morro. Entretanto, essa interpretação ganha relevância se considerarmos que os ex-soldados poderiam ter percebido a existência da cruz como uma reminiscência da guerra, que se tornaria mais um forte componente indutor da alteração do nome.

A compilação de Valladares (2000) sobre a presença da planta na vertente carioca reforça o papel dos moradores na denominação do morro, mas não parece plausível. Não há registro de Cnidoscolus quercifolius no Rio de Janeiro. São ambientes muito distintos, dadas as diferenças climáticas e pedológicas entre o sertão baiano e o Rio de Janeiro. É provável que a elevada diversidade de plantas com o mesmo nome popular tenha influenciado a afirmação. A ocorrência da favela-branca no Rio de Janeiro é possível, mas, como mencionado anteriormente, não corresponde à planta que originou o topônimo canudense. A perspectiva de associar a resistência dos conselheristas a dos moradores do morro indicaria uma denominação externa, um juízo de valor dos moradores da cidade, que colaboraria com a disseminação do termo.

A interpretação de Pasternak (2006), sobre a semelhança da distribuição das plantas e dos barracos, reforça a idéia de denominação pelos moradores do morro, pois é pouco provável que uma associação dessa natureza pudesse ser feita pelos moradores cariocas, que não conheciam as características de Canudos. Essa relação faz ainda mais sentido quando se considera a descrição de Euclides: o Alto da Favela é "desnudo e áspero". Portanto, a dispersão da planta parece caracterizar com fidelidade a natureza esparsa dos barracos, no início do processo de ocupação do morro Providência.

Tampouco parece haver discordância sobre a generalização do termo favela. A denominação e a disseminação foram fruto de processos complementares, que envolveram diferentes grupos e razões. A denominação (nome próprio: Morro da Favela) teria sido promovida pelo grupo de moradores da encosta, mas sua disseminação (substantivo: favela) teria sido consagrada pelos moradores da cidade, num período posterior. 
Não há dúvidas quanto à relação de Os Sertões e a favela. A obra de Euclides da Cunha teve papel fundamental na divulgação e cristalização do termo. O sucesso editorial da narrativa colaborou com o processo de formação de um imaginário coletivo sobre a favela. Euclides da Cunha provavelmente não conheceu o significado atual do substantivo favela, mas certamente colaborou com a inserção do topônimo no vocabulário de uma parte da população brasileira da época.

No que se refere à planta, pôde-se constatar as diferentes denominações da espécie. Houve divergências entre os taxonomistas (Jatropha/Cnidoscolus), existem muitos sinônimos e nomes populares, mas a planta Cninodoscolus quercifolius é a que melhor corresponde à descrição de Euclides da Cunha.

A origem da palavra favela é muito mais complexa do que a do cortiço. Embora a percepção da qualidade de vida, no senso comum, tenda a ser pior no cortiço do que na favela, sua procedência é mais singela. O cortiço é decorrente da associação hospedagem/colméia. Consiste no abrigo usado no processo de produção de mel e possui características semelhantes às casas de cômodos ou habitações coletivas: grande quantidade de moradores, espaços exíguos e barulho significativo.

A origem da palavra cortiço permite postular uma associação mais simples e direta ao substantivo favela. Considera-se pertinente supor uma relação entre as características físicas da fava, faveiro ou faveleiro e os barracos. Assim, seria factível supor a associação da agressividade dos moradores do morro da Favela à dos tricomas da planta. Também seria de se esperar a associação entre a resistência da planta, que ocorre em condições climáticas muito severas, e dos habitantes do morro, que sobreviviam em condições de extrema precariedade. Embora não tenham sido encontradas referências bibliográficas que mencionem essas interpretações, acredita-se que elas também possam ter contribuído nesse processo de disseminação do termo favela.

\section{CONSIDERAÇÕES FINAIS}

A favela, um dos principais assentamentos urbanos precários brasileiros, é considerada produto da rápida expansão populacional e do déficit habitacional do Rio de Janeiro, no final do século XIX. Contribuíram para isso as circunstâncias do fim das Guerras do Paraguai e de Canudos, a abolição da escravatura e as crises da agricultura.

O surgimento dos assentamentos urbanos precários, mostram as evidências, remete a uma conjunção de dois principais fatos: demolição do maior cortiço da cidade, o Cabeça de Porco, e a autorização para que militares construíssem barracões no morro de Santo Antônio. A denominação favela ocorreria posteriormente, com a chegada dos ex-combatentes ao morro da Providência, re-batizado de Morro da Favela. Esse nome próprio se tornou substantivo, principalmente, pela ação de jornalistas e escritores, no qual se destaca Euclides da Cunha, que ajudaram a formar o imaginário coletivo sobre a favela.

A planta descrita por Euclides da Cunha deve ser a Cninodoscolus quercifolius. Sua ocorrência é dispersa e, diferentemente do que se supunha, não recobre o Alto da Favela, colina da região de Canudos, onde combateram e, posteriormente, acamparam as expedições militares contra Antonio Conselheiro. Sua distribuição é esparsa e sua ocorrência, possivelmente, se dava nas partes baixas da encosta.

Dentre as interpretações para a substituição do nome, de morro da Providência para morro da Favela, a mais plausível destaca aspectos militares do cenário de guerra: 1) o ponto estratégico, no qual as tropas republicanas sofreram uma emboscada e, posteriormente, de onde lançaram ataques que permitiram a vitória republicana sobre os seguidores do beato, 2) a topografia, semelhante em Canudos e no Rio de Janeiro, que indica uma metáfora entre as privações durante e após os combates. 


\section{AGRADECIMENTOS}

À Coordenação de Aperfeiçoamento de Pessoal de Nível Superior (CAPES), pelo financiamento do estágio pós-doutoral no Institut des Hautes Études de L'Amérique Latine - Université Paris III Sourbonne Nouvelle (2008-2009). Processo BEX 3373/08-8.

Ao Professores Doutores Alessandra Bizerra (IB-USP), André Laurênio de Melo (UFRPE) e Odaci Fernandes de Oliveira (UFERSA) pelos inestimáveis esclarecimentos sobre a planta.

À Mariana Abrantes Giannotti, pela revisão e sugestões.

\section{REFERÊNCIA BIBLIOGRÁFICAS}

ABREU, M.A., Reconstruindo uma história esquecida: origem e expansão inicial das favelas do Rio de Janeiro. Espaço \& Debates. v.37, p.34-46, 1994.

ABREU, M.A., VAZ, L.F. Sobre as origens da favela. In: IV Encontro Nacional da ANPUR. Salvador. Anais. Associação Nacional de Pós-graduação e Pesquisa em Planejamento Urbano e Regional. 1991. p.481-492. BICALHO, M.F. A cidade do Rio de Janeiro e o sonho de uma capital americana: da visão de D. Luís da Cunha à sede do vice-reinado (1736-1763). História (São Paulo). Vol 30, n. 1. Disponível em: http://www. scielo.br/scielo.php?script=sci_arttext\&pid=S0101-90742011000100003\&lang=pt Acesso em: 30 nov 2011 . DOI: $10.1590 / \mathrm{S} 0101-90742011000100003$.

CARDOSO, A.L. Contextualização/caracterização. In: BRASIL, Política habitacional e integração urbana de assentamentos precários: parâmetros conceituais, técnicos e metodológicos. Ministério das Cidades, 2008. p.13-45. Disponível em: <http://www.cidades.gov.br/images/stories/ArquivosSNH/ArquivosZIP/ PH_e_Integracao_de_AssPrec.rar>. Acesso em: 01 jun 2011.

CHALHOUB, S. Cidade Febril: cortiços e epidemias na corte imperial. São Paulo: Cia da Letras, 1996. 250p. CORDEIRO, I., SECCO, R. 2010. Cnidoscolus in Lista de Espécies da Flora do Brasil. Jardim Botânico do Rio de Janeiro. Disponível em: <http://floradobrasil.jbrj.gov.br/2010/FB017494>. Acesso em: 01 jun 2011. CRUZ, H.D. Os morros cariocas no novo regime: notas de reportagem. Rio de Janeiro: S/E. 1941. 102p. CUNHA, E. Os sertões. Edição Crítica GALVÃO, W.N. São Paulo: Brasiliense. 1985. 728p.

CUNHA, M.A. A chama da nacionalidade: ecos da Guerra do Paraguai. Rio de Janeiro: Biblioteca do Exército Editora. 2000, 159p.

DAVIS, M. Planeta favela. São Paulo: Ed. Boi Tempo. 2006, 272p.

DNOCS, Departamento Nacional de Obras contra as Secas. Outorga de barragem. Disponível em: $<\mathrm{http}: / /$ www.dnocs.gov.br/php/comunicacao/noticias.php?f_header=1\&f_opcao=imprimir\&f_registro $=465 \& p$ view=short $>$. Acesso em: 24 mai 2011.

IBGE. Malha municipal digital do Brasil. 2005. Rio de Janeiro: Fundação Instituto Brasileiro de Geografia e Estatística. CD-ROM.

LORENZI, H. Árvores brasileiras: manual de identificação e cultivo de plantas arbóreas nativas do Brasil. $2^{\mathrm{a}}$ Ed. Nova Odessa: Instituto Plantarum. 2002. 380p.

MEDINA, C.A. A favela e o demagogo. São Paulo: Martins Editora. 1964. 101p.

MELO, A. L. de; SALES, M. F. de. O gênero Cnidoscolus Pohl (Crotonoideae-Euphorbiaceae) no Estado de Pernambuco, Brasil. Acta Bot. Bras., São Paulo, v. 22, n. 3, Sept. 2008 . Disponível em: $<$ http://www. scielo.br/scielo.php?script=sci_arttext\&pid $=\mathrm{S} 0102-33062008000300017 \& \operatorname{lng}=\mathrm{en} \& \mathrm{nrm}=\mathrm{iso}>$. Acesso em: 28 Abr. 2011. DOI: 10.1590/S0102-33062008000300017.

OLIVEIRA, J.S.; MARCIER, M.H. A palavra é: favela. In: ZALUAR, A.; ALVITO, M. Um século de favela. Rio de Janeiro: Fundação Getúlio Vargas. 1998. p.61-113.

PASTERNAK, S. São Paulo e suas favelas. Revista do Programa de Pós Graduação em Arquitetura e Urbanismo da FAU/USP, São Paulo. v. 27, p. 176-197, 2006.

PASTERNAK, S. O Desafio da Mensuração. In: BRASIL, Política habitacional e integração urbana de assentamentos precários: parâmetros conceituais, técnicos e metodológicos. Ministério das Cidades. 
2008. p.93-110. Disponível em: $<$ http://www.cidades.gov.br/images/stories/ArquivosSNH/ArquivosZIP/ PH_e_Integracao_de_AssPrec.rar>. Acesso em 01 jun 2011.

ROCHA, O.P. A era das demolições: cidade do Rio de Janeiro 1870-1920. Rio de Janeiro: Secretaria Municipal de Cultura, 1995. 97p.

SAGMACS. Aspectos humanos da favela carioca. O Estado de São Paulo, suplementos especiais, abril. 1960. UN-HABITAT, The challenge of slums. Global report on human settlements 2003. London: Earthscan. 2003, 310p.

VALLADARES, L.P. A gênese da favela carioca: a produção anterior às ciências Sociais. Revista Brasileira de Ciências Sociais. vol. 15, no. 44, p.5-34, 2000.

VALLADARES, L.P. A invenção da favela: do mito de origem a favela.com. Rio de Janeiro: FGV Editora. 2005. 204p.

VAZ, L. F. Dos cortiços às favelas e aos edifícios de apartamentos - a modernização da moradia no Rio de Janeiro. Análise Social - Revista do Instituto de Ciências Sociais da Universidade de Lisboa, 1994a, v.24, n.127, p. 581-597. 1994a.

VAZ, L.F. Uma história da habitação coletiva na cidade do Rio de Janeiro. 1994b. 229p. Tese (Doutorado). Faculdade de Arquitetura e Urbanismo, Universidade de São Paulo. São Paulo. 1994.

ZYLBERBERG, S. Morro da Providência: memórias da Favella. Rio de Janeiro: Secretaria Municipal de Cultura, Turismo e Esportes. 1992. 122p.

Trabalho enviado em setembro de 2011 